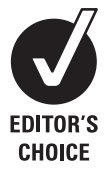

- A Chinese version of this manuscript is available online only at http://injuryprevention. bmj.com/content/vol14/issue5

${ }^{1}$ The George Institute for International Health, University of Sydney, Sydney, Australia;

${ }^{2}$ The George Institute, China and Peking University Health Science Center, Beijing. People's Republic of China; ${ }^{3}$ School of Public Health, Curtin University of Technology, Perth, Australia ${ }^{4}$ Shantou University Medical College, Shantou, People's Republic of China

Correspondence to: Professor M Stevenson, PO Box M201, Missenden Road, Sydney, NSW 2050, Australia; mstevenson@george.org.au

Accepted 10 June 2008

\title{
Reducing the burden of road traffic injury: translating high-income country interventions to middle-income and low-income countries
}

\author{
M Stevenson, ${ }^{1} \mathrm{~J} Y \mathrm{u}_{1}{ }^{2} \mathrm{D}$ Hendrie, ${ }^{3} \mathrm{~L}-\mathrm{P} \mathrm{Li},{ }^{4} \mathrm{R}$ Ivers, ${ }^{1} \mathrm{Y} \mathrm{Zhou}_{1}{ }^{2} \mathrm{~S} \mathrm{Su},{ }^{1} \mathrm{R}$ Norton ${ }^{1}$
}

\begin{abstract}
Objective: To increase seat belt restraint use in Guangzhou City, People's Republic of China.

Design: Comparison group pre-test, post-test design.

Setting: Guangzhou City.

Interventions: Interventions to increase the prevalence of seat belt use in high-income countries (enhanced training and enforcement practices along with raising of public awareness) were adapted and implemented in Guangzhou. The prevalence of seat belt use was determined before and after the introduction of the 12month intervention. Seat belt prevalence was also examined over the same time period in the neighboring city of Nanning, and an incremental cost-effectiveness analysis of the intervention was undertaken.
\end{abstract}

Main outcome measures: Prevalence rates and incremental cost effectiveness ratios.

Results: A $12 \%$ increase in seat belt use was observed in Guangzhou over the study period, increasing from a prevalence of $50 \%$ before (error range $30-62 \%$ ) to $62 \%$ after (error range 60-67\%) ( $p<0.001)$ the intervention; an absolute change difference between the intervention and reference city of $20 \%$ was achieved. The incremental cost-effectiveness ratio of the intervention was $¥ 3246$ (US\$418) per disability-adjusted life year saved.

Conclusions: This city-wide intervention demonstrates that it is possible to increase the prevalence of seat belt use using similar methods to those used in high-income countries and, importantly, that such an approach is cost-effective.

In the People's Republic of China, injuries are the leading cause of death from age 1 to 44 years, accounting for approximately 750000 deaths and 3.5 million hospitalizations each year. ${ }^{1}$ Given that motor vehicle production has tripled since the early $1990 \mathrm{~s},{ }^{2}$ it is not surprising that much of the injuryrelated mortality and morbidity is due to road traffic injury. Over a 45-year period (1951-1999), road traffic fatalities and serious injuries in the country increased 4-fold and 10-fold, respectively, ${ }^{3}$ with an estimated 100000 people dying from road traffic injury each year. ${ }^{4}$ The increase in road traffic-related mortality and morbidity reflects, in part, the epidemiological transition that has been occurring across much of the country, but particularly among the eastern and south-western provinces, over the past two decades. The resulting societal burden from road traffic injuries in the People's Republic of China is overwhelming and there is an urgency to implement cost-effective interventions particularly in the mega cities such as Beijing, Shanghai, and Guangzhou, where motorization is taking place at a rapid rate. ${ }^{5}$
In 2004, the World Report on Road Traffic Injury Prevention ${ }^{6}$ highlighted an array of intervention strategies that have been shown to be effective in high-income countries. However, the report also highlighted the paucity of knowledge about the effectiveness of these strategies in lowincome and middle-income countries; seatbelts are a prime example.

There is unequivocal evidence that seat belts are efficacious, with recent research ${ }^{7}$ indicating that the risk of death is significantly reduced (by a minimum of $45 \%$ ) in drivers restrained by a seat belt compared with those unrestrained. Furthermore, there is evidence from systematic reviews ${ }^{8}$ that comprehensive intervention programs to increase seat belt use are effective in increasing the prevalence of seat belt use. However, evidence on the effectiveness of these interventions is currently only available from high-income countries.

In 1993, the Ministry of Health of the People's Republic of China instituted a regulation requiring all vehicles less than $6 \mathrm{~m}$ in length and/or carrying fewer than 20 passengers to have seat belts fitted in the front seats of the vehicle and their mandatory use by drivers and front-seat passengers. Despite the availability of seat belts in almost all vehicles, the reported rates of use are low; a recent observational study of seat belt use among taxi drivers in Beijing found seat belt use as low as $7.7 \%,{ }^{9}$ and a national survey found that only $22 \%$ of respondents had ever worn a seat belt over the 30 days preceding the survey. ${ }^{10}$

This study sought to determine whether an intervention to increase seat belt use that has been found to be highly effective in high-income countries $^{8}$ could be successfully implemented in a middle-income country such as the People's Republic of China. In addition, the study aimed to determine the cost-effectiveness of the intervention, which was implemented in one of the mega cities, Guangzhou.

\section{METHODS}

\section{Intervention}

The intervention had four components-enhanced police training and enforcement, social marketing, and health education - with the latter two focused on raising public awareness. The intervention was implemented over a 12-month period (September 2005 to August 2006) and was modeled on the outcome from a systematic review that recommended these components as effective in increasing seat belt use. ${ }^{8}$ 
The enhanced police training and enforcement component involved traffic police educators providing skills-based training and strategies for enhancing the current traffic police enforcement practices. The training followed the "train-the-trainer" model whereby selected traffic police $(n=50)$ undertook an intensive 1-week course which included topics such as safe vehicle interception, safe checkpoint and road block operations, and overcoming barriers to effective traffic enforcement. The trained personnel then hosted the same course for all traffic police in Guangzhou. In total, 1125 police officers (83\% of the total personnel) were provided with this training.

Beyond this, the enforcement component involved setting targets for the issuance of infringement notices for drivers not using the available seat belt (as well as infringement notices to drivers carrying unrestrained front-seat passengers). The enforcement involved high-profile mobile patrols combined with static covert operations involving 100-200 police officers at numerous locations throughout Guangzhou. The operation was conducted in five phases over the 12-month period, each of 2 3 days duration. As the intervention aimed to increase seat belt use among not only drivers but also front-seat passengers, the drivers were issued with a fine if the front-seat passenger was not using the available seat belt. A total of 11000 vehicles were stopped and 2110 infringement tickets issued during the five phases; this resulted in a $40 \%$ increase in the usual issuance of tickets (176 vs 120 tickets issued per day).

The aim of the social marketing and health education components of the intervention was to raise public awareness of the safety benefits of seat belts and the need to be restrained by a seat belt while traveling in a vehicle. The target audience for the social marketing campaign (which involved television and radio commercials as well as roadside billboard advertisements (fig 1) and bus signage) was the driving population, including professional drivers, taxi drivers, and drivers in government organizations. The campaign involved a total of 950 television advertisements of $30 \mathrm{~s}$ duration, 3240 radio advertisements of $15 \mathrm{~s}$ duration, as well as an array of printed marketing materials. Taxi companies, driver training school instructors, and teachers of primary school students were targeted as part of the health education component. A $2 \mathrm{~h}$ course was delivered to 120 taxi company managers, educational materials were provided to teachers of primary schools in

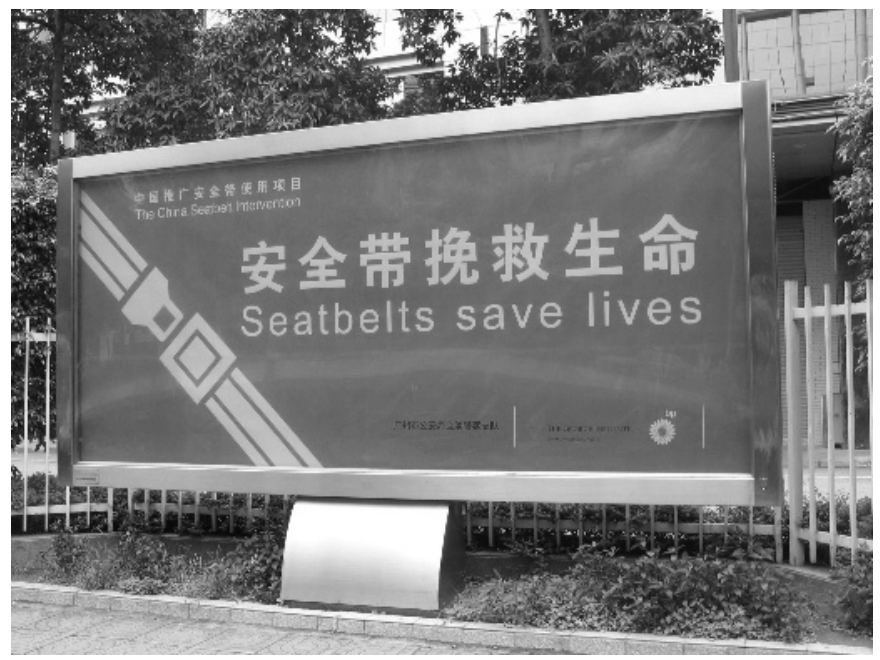

Figure 1 Roadside billboard reminding drivers about the importance of using a seat belt. the city, and a series $(n=8)$ of $1 \mathrm{~h}$ lectures were delivered to driver training schools. The educational component for these activities focused on the known benefits of seat belts, the current laws, and the fitting and correct use of restraints.

\section{Study design and evaluation}

The effectiveness of the intervention was examined using a reference group in a pre-test, post-test comparison design. Guangzhou was selected as the intervention city, and Nanning was selected as the reference city. The choice of Guangzhou was determined in part by the interest of the provincial government and in part by its poor road safety record (it has the second highest road fatality rate of the eastern seaboard cities), ${ }^{11}$ and Nanning was selected on the basis of cost-efficiencies. Each city has an extensive road network, and both are provincial capitals, although Nanning is notably smaller, and has a greater proportion of motorcycle use compared with Guangzhou (table 1).

The prevalence of seat belt use was the primary outcome measure. To estimate the prevalence rate of seat belt use, a random sample of the road network in both the intervention and reference cities was observed at two time points: April-May 2005 (pre-intervention) and September-October 2006 (postintervention). There is almost no seasonal variation across the selected months. ${ }^{12}$ As pilot research highlighted a variation in seat belt use by road type, observational sites were stratified by road hierarchy (local roads, main roads, and expressways). Observations of seat belt use-for all drivers and front-seat passengers-were undertaken over a 7-day period and at various times across the day (8:01am to $6 \mathrm{pm} ; 6: 01 \mathrm{pm}$ to $9 \mathrm{pm})$ by trained observers. For multi-lane roads, only vehicles traveling on the lane closest to the curb on which the observer was stationed were included in the observational surveys. A total of 34321 and 28807 vehicles were observed in the intervention city during the two (pre-intervention and post-intervention) observational periods, respectively, and 26535 vehicles were observed before and 25485 after the intervention in the reference city. Seat belts were documented as being worn if the three-point shoulder belt was worn tightly across the chest of the occupant and there was no sign of a bull clip or clamp/ nail (to prevent recoil of the belt if not worn).

The prevalence rate was calculated as the number of frontseat occupants correctly using a seat belt over the total number of front-seat occupants observed. The error range was the prevalence rate observed over each day of the pre- and postintervention periods. Two-sample $z$ tests and the corresponding 95\% CIs were computed and used to compare the changes between pre-intervention and post-intervention prevalence rates in each city.

An incremental cost-effectiveness analysis was also undertaken with the net cost and benefits of the intervention

Table 1 Demographic features of the intervention and reference cities

\begin{tabular}{lll}
\hline Demographics & $\begin{array}{l}\text { Guangzhou } \\
\text { (intervention) }\end{array}$ & $\begin{array}{l}\text { Nanning } \\
\text { (reference) }\end{array}$ \\
\hline Population & 11787100 & 6697000 \\
Annual income per capita (¥) & 15003 & 10078 \\
Length of highways $(\mathrm{km})$ & 5438 & 6127 \\
Vehicle fleet & 1722105 & 875822 \\
$\quad$ Motorcycles & $59.7 \%$ & $75.2 \%$ \\
Cars & $38.7 \%$ & $12.4 \%$ \\
Taxis & $0.9 \%$ & $0.4 \%$ \\
\hline
\end{tabular}


Table 2 Component costs and the incremental costeffectiveness ratio (ICER)

\begin{tabular}{lc}
\hline Component & Amount (¥) \\
\hline Intervention costs & \\
$\quad$ Enhanced police training and & 1013503 \\
enforcement & \\
$\quad$ Social marketing & 816468 \\
$\quad$ Health education & 289327 \\
$\quad$ Project management & 1005428 \\
Total intervention costs & 3124726 \\
Cost savings & 1404149 \\
Net costs of intervention & 1720577 \\
DALYs saved & 530 \\
ICER: net cost per DALY saved & 3246 (US\$418) \\
\hline
\end{tabular}

DALY, disability-adjusted life year.

compared with standard practice, ie, no enhanced program to promote seat belt use. The perspective for the analysis was societal, and details of the component costs and the incremental cost-effectiveness ratio (ICER) are described in table 2. A time frame of 1 year was adopted for the analysis, which assumed that any increase in seat belt use did not extend beyond the year of the intervention.

All additional costs of implementing the intervention, if it were to become an ongoing program, were included in the analysis. These additional costs consisted of the expenditure on each of the four components involved in the intervention as well as the cost of overall project management. Costs for the analysis were calculated directly from study records or from the relevant government agencies. Infringement costs (fines) for lack of seat belt use were not included in the cost of the intervention; from a societal perspective, these costs can be considered simply as transfer payments. The cost-effectiveness analysis incorporated the cost savings from the reduction in hospital admissions resulting from the intervention; this was based on the observed increase in seat belt use due to the intervention and the assumption that seat belts reduce fatal and serious injuries by up to $45 \%{ }^{7}$ However, in the absence of specific documentation on front-seat occupant fatality and serious injury, police estimates were used. These suggested that $30 \%$ of the reported fatalities and seriously injured casualties were motor vehicle occupants and that $65 \%$ of these were frontseat occupants. Other potential savings in resource use, such as other medical expenses, police investigation costs, and workplace disruption costs, were excluded. The cost of a hospital admission was assumed to be ¥9298 (the average cost at a western medicine ministry level and city level hospital in Guangzhou). ${ }^{13}$ Costs presented in the cost-effectiveness analysis are expressed in 2006 Chinese yuan ( $¥)$, with ICERs expressed in US dollars (US\$).

The health gain from preventing fatalities and injuries through increased seat belt use was measured using disabilityadjusted life years (DALYs). Data from the evaluation of the intervention's effectiveness in increasing seat belt use provided the starting point for calculating the DALYs gained from the intervention. An ICER was calculated as the cost of the intervention less the cost savings from fewer hospital admissions, divided by the number of DALYs saved from the increase in seat belt use.

\section{RESULTS}

Table 3 gives baseline observations for both the intervention and reference cities. The baseline results highlight substantial differences between the two cities in driver seat belt use particularly by road type, the time of day, and vehicle type observed. Importantly, the prevalence of seat belt use was significantly lower in the intervention city than the reference city, with the prevalence for some observations (eg, drivers of taxis) 30\% lower in the intervention city than in the reference city. Overall, there was no significant difference in the prevalence of seat belt use by front-seat passengers between the two cities. Please note that passenger in table 3 refers to front-seat passenger only.

The prevalence of seat belt use by drivers increased significantly from $50 \%$ (error range $30-62 \%$ ) to $62 \%$ (error range $60-67 \%)(p<0.001)$ for the intervention city, compared with a significant decrease from $64 \%$ (error range $28-74 \%$ ) to $56 \%$ (error range $41-62 \%$ ) in the reference city $(p<0.001)$. For front-seat passengers, there was an increase from $40 \%$ (error range $17-53 \%$ ) to $53 \%$ (error range $47-55 \%$ ) in the intervention city, whereas the reference city experienced a decline in seat belt use over the same period (38\% (error range 18-45\%) to $33 \%$ (error range 19-42\%)). Overall, there was a 12\% (95\% CI 12\% to $13 \%, \mathrm{p}<0.001)$ increase in the prevalence of seat belt use in the intervention city and an $8 \%(95 \% \mathrm{CI}-8 \%$ to $7 \%, \mathrm{p}<0.001)$ decline in the reference city (fig 2).

The greatest change in the prevalence of seat belt use by drivers was observed on local and main roads in the intervention city. The increase in seat belt use by drivers after the intervention was $16 \%$ (95\% CI $14 \%$ to $17 \%, \mathrm{p}<0.001$ ) on local roads and $15 \%$ (95\% CI $14 \%$ to $17 \%, \mathrm{p}<0.001)$ on main roads. For drivers observed on expressways, the increase in seat belt use was $5 \%$ ( $95 \%$ CI $4 \%$ to $7 \%, p<0.001)$, with $68 \%$ of all drivers in Guangzhou correctly using their seat belts on expressways after the intervention (fig 3 ). The prevalence of seat belt use also increased significantly for both male $(12 \%$, $95 \%$ CI $11 \%$ to $13 \%, \mathrm{p}<0.001)$ and female $(18 \%, 95 \%$ CI $14 \%$ to $21 \%, \mathrm{p}<0.001)$ drivers in the intervention city (fig 4).

On the basis of the observed increase in seat belt use in the intervention city and the known effectiveness of seat belt use, the likely reduction in road fatalities and serious injuries from the intervention would have been $7.0 \%$ (estimated by $0.12 \times(0.45 /(1-(0.47 \times 0.45))$. Therefore, the intervention was estimated to have reduced the number of fatalities of front-seat motor vehicle occupants by 24 and the number of front-seat motor vehicle occupants who sustained serious injury by 143 . The number of DALYs saved from each fatality and each seriously injured casualty prevented was calculated as 18.63 and 0.58 , respectively, giving a present value for the total number of DALYs saved from the intervention of 530. Given the cost of implementing the intervention and the associated cost savings, the ICER of the intervention compared with no enhanced program to promote seat belt use was $¥ 3246$ per DALY saved or the equivalent of US\$418 per DALY saved.

\section{DISCUSSION}

The results suggest that road safety interventions that are highly effective in high-income countries ${ }^{14}$ can be translated to and successfully implemented (as measured by changes in the prevalence of seat belt use) in a middle-income country such as the Peoples' Republic of China.

The prevalence of seat belt use by drivers and front-seat passengers had increased significantly after the intervention in Guangzhou, with an absolute change difference between the intervention and reference city of $20 \%$. Over the period of the study, significant increases in the prevalence of seat belt use 
Table 3 Baseline factors for the intervention and reference cities

\begin{tabular}{|c|c|c|c|c|}
\hline \multirow[b]{2}{*}{ Key factors } & \multicolumn{2}{|c|}{ Guangzhou (intervention) } & \multicolumn{2}{|c|}{ Nanning (reference) } \\
\hline & No & $\begin{array}{l}\text { Prevalence } \\
(\%)\end{array}$ & No & $\begin{array}{l}\text { Prevalence } \\
\text { (\%) }\end{array}$ \\
\hline \multicolumn{5}{|c|}{ Driver seat belt use by road type } \\
\hline Local roads & 5743 & 45 & 7516 & 60 \\
\hline Main roads & 4842 & 44 & 8301 & 66 \\
\hline Expressways & 6447 & 63 & 1145 & 86 \\
\hline \multicolumn{5}{|c|}{ Driver seat belt use by gender } \\
\hline Male & 16208 & 50 & 15479 & 64 \\
\hline Female & 811 & 58 & 1481 & 63 \\
\hline \multicolumn{5}{|c|}{ Driver seat belt use by time } \\
\hline Week day & 4637 & 51 & 4987 & 70 \\
\hline Week night & 4122 & 49 & 3984 & 62 \\
\hline Weekend day & 4603 & 52 & 4290 & 64 \\
\hline Weekend night & 3670 & 48 & 3701 & 58 \\
\hline \multicolumn{5}{|c|}{ Driver seat belt use by vehicle type } \\
\hline Car & 12679 & 61 & 10234 & 68 \\
\hline Taxi & 3112 & 30 & 5816 & 60 \\
\hline Other & 1224 & 40 & 893 & 46 \\
\hline \multicolumn{5}{|c|}{ Passenger seat belt use by road type } \\
\hline Local roads & 1364 & 31 & 1376 & 32 \\
\hline Main roads & 1470 & 33 & 1542 & 37 \\
\hline Expressways & 2801 & 51 & 612 & 68 \\
\hline \multicolumn{5}{|c|}{ Passenger seat belt use by gender } \\
\hline Male & 3652 & 39 & 2384 & 39 \\
\hline Female & 1951 & 41 & 1144 & 35 \\
\hline \multicolumn{5}{|c|}{ Passenger seat belt use by time } \\
\hline Week day & 1437 & 40 & 983 & 42 \\
\hline Week night & 1241 & 38 & 839 & 37 \\
\hline Weekend day & 1715 & 43 & 898 & 38 \\
\hline Weekend night & 1242 & 38 & 810 & 34 \\
\hline \multicolumn{5}{|c|}{ Passenger seat belt use by vehicle type } \\
\hline Car & 4411 & 46 & 2761 & 45 \\
\hline Taxi & 800 & 26 & 561 & 24 \\
\hline Other & 416 & 26 & 199 & 24 \\
\hline
\end{tabular}

were observed in Guangzhou across most factors: the gender of the driver, the type of road, and the type of vehicle (with a $26 \%$ increase in restraint use by taxi drivers). The increased prevalence observed in this study reflects studies in high-income countries in which the same interventions were implemented, achieving a median increase in seat belt use of $16 \% .{ }^{14}$ If one considers that only half the desired level of enforcement (as

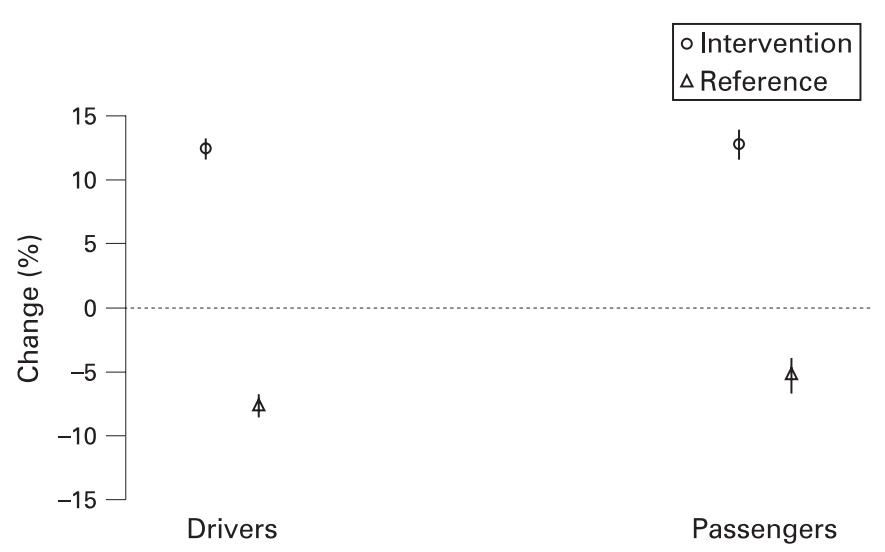

Figure 2 Overall change in the prevalence of seat belt use by car occupants between intervention and reference cities. The vertical solid lines represent $95 \% \mathrm{Cl}$. requested by the independent police educator contracted to assist with the intervention) was delivered, it is likely that, with greater resources, one could achieve a substantially higher prevalence of seat belt use.

There is now an array of cost-effective road safety interventions for low-income and middle-income countries ranging from traffic calming to reduce speed (US\$5 per DALY saved) to

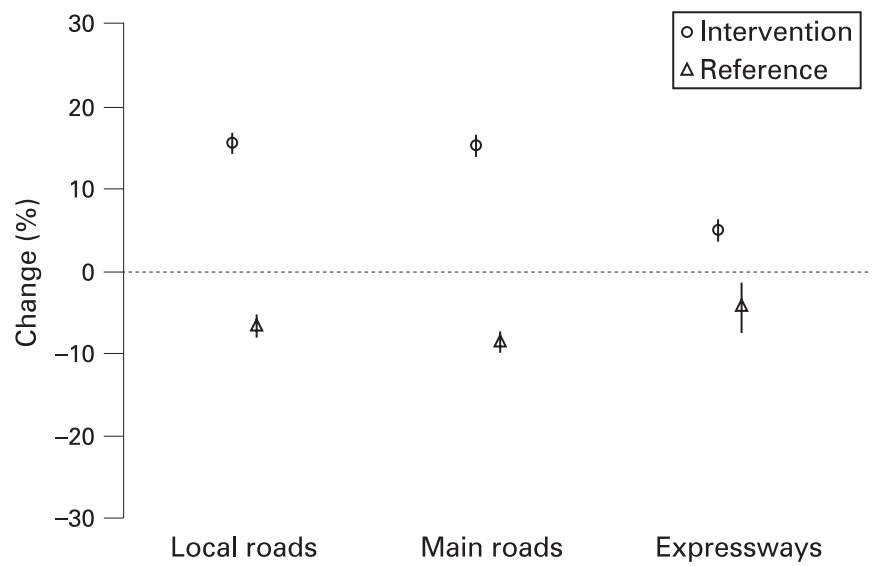

Figure 3 Overall change in the prevalence of seat belt use for drivers by road type between intervention and reference cities. The vertical solid lines represent $95 \% \mathrm{Cl}$. 


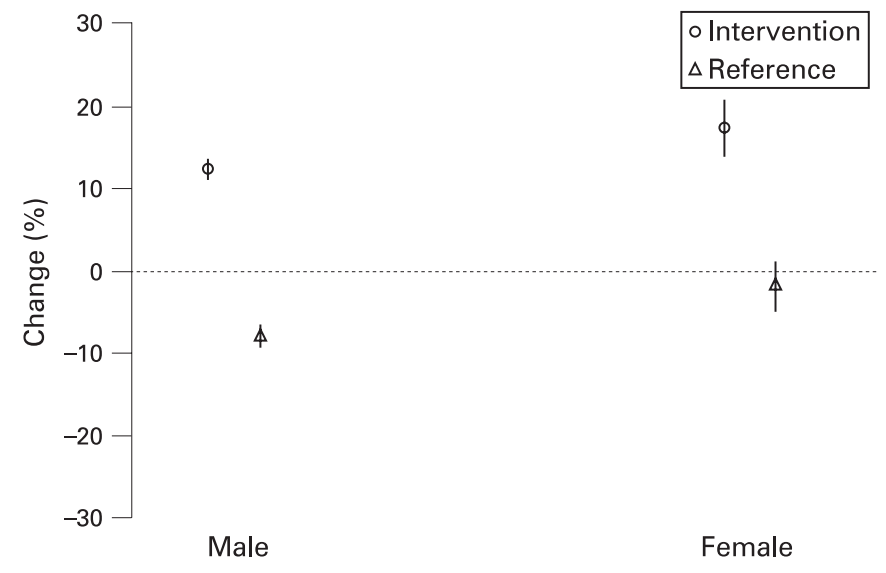

Figure 4 Overall change in the prevalence of seat belt use by male and female drivers. The vertical solid lines represent $95 \% \mathrm{Cl}$.

motorcycle helmet legislation (US $\$ 467$ per DALY saved). ${ }^{15}$ If one considers interventions where the cost-effectiveness ratio is less than the country's per capita gross domestic product (GDP) to be extremely cost-effective, ${ }^{16}$ then the current intervention (with an ICER of $¥ 3246$ (US\$418) per DALY saved, which is only $42 \%$ of China's reported GDP in $2006^{17}$ ) is highly costeffective.

Despite the significant increase in the prevalence of seat belt use in the intervention city, it remains low compared with highly motorized countries. For example, the post-intervention prevalence of seat belt use in the intervention city (62\%) is far below that in the USA $(82 \%)^{18}$ and Australia (95\%). ${ }^{19}$ A greater intensity of intervention activities over a longer period will be needed to increase the prevalence of seat belt use to that of highincome countries.

There are a number of alternative explanations for the increased prevalence of seat belt use in the intervention city. The first is that the observed changes are due to activities other than the intervention, eg, heavily tinted windows on vehicles (which obscure detection of seat belt use) are now prohibited. However, this change was implemented after the intervention and therefore would not have contributed to the results observed in the study. The government has also increased the financial penalty for non-use (or incorrect use) of the seat belt from $¥ 20$ to $¥ 200$. There is good evidence that higher fines are effective in increasing the prevalence of seat belt use, ${ }^{20}$ but this measure was also introduced before the intervention, in both cities. Importantly, both of these legislative changes were nationwide and would therefore have affected the reference city equally.

The most obvious alternative explanation is that the changes in the prevalence estimates of restraint use are biased. This is a possibility given that the observers were not blinded to the intervention status of the city. However, to minimize this potential bias, all observers followed a standardized protocol, underwent a 1-day training program, and were party to random roadside audits by the researchers to ensure that protocols were adhered to. In addition, the same observers were used for both pre-intervention and postintervention observations. Despite these approaches, we cannot entirely dismiss the possibility of biased estimates, albeit small.

\section{What is already known on this topic}

- Comprehensive intervention programs are effective in increasing the prevalence of seat belt use.

- The prevalence of seat belt use is low in The People's Republic of China.

\section{What this study adds}

- Road safety interventions used in high-income countries can be successfully translated to middle-income (and potentially low-income) countries.

- Comprehensive seat belt interventions are highly costeffective; governments in rapidly motorizing countries need to be encouraged to implement such interventions.

\section{IMPLICATIONS FOR PREVENTION}

This study suggests that it is possible to successfully implement in middle-income countries specific road safety interventions that are used in high-income countries. Given the speed at which motorization is taking place in these growing economies, there is an urgency to implement these and other effective interventions to reduce the burgeoning incidence of road trauma.

Acknowledgements: The Ministry of Public Security and the Ministry of Health of the People's Republic of China, Guangzhou Traffic Command and Control Center and the World Health Organization supported this intervention. We thank BP and The George Foundation for International Health for funding the intervention and Dr Zhang Junhua, Dr Li Gongli, and the roadside observers for their assistance. We are grateful to Roma Keswani for research assistance and Dr Stephen Jan for helpful comments, and also to Assistant Commissioner (retired) Ray Shuey. MS is supported by a National Health and Medical Research Council Fellowship, and RI by a National Health and Medical Research Council Career Development Award.

Competing interests: None.

\section{REFERENCES}

1. Ministry of Health, People's Republic of People's Republic of China. People's Republic of China National Health Statistics, 1999. Beijing: Press of People's Health 2000.

2. Zhou Y, Baker TD, Rao K, et al. Productivity losses from injury in People's Republic of China. Inj Prev 2003;9:124-7.

3. Wang S, Chi G, Jing C, et al. Trends in road traffic crashes and associated injury and fatality in the People's Republic of People's Republic of China, 1951-1999. Inj Cont Saf Promot 2003;10:83-7.

4. Ye J. Car crackdown creates controversy. China Daily. 28 May 2004. http://www. chinadaily.com.cn/english/doc/2004-05/28/content_334625.htm.

5. National Bureau of Statistics. People's Republic of China statistical yearbook, 2004. Beijing: People's Republic of China Statistics Press.

6. Peden M, Scurfield R, Sleet D, et al. World report on road traffic injury prevention. Geneva: World Health Organisation, 2004.

7. Cummings $\mathbf{P}$, Wells J, Rivara F. Estimating seat belt effectiveness using matched pair cohort methods. Accid Anal Prev 2003;35:143-9.

8. Dinh-Zarr TB, Sleet DA, Shults RA, et al. Reviews of evidence regarding interventions to increase the use of safety belts. Am J Prev Med 2001:21(4S):48-65

9. Passmore J, Ozanne-Smith J. Seatbelt use amongst taxi drivers in Beijing, People's Republic of China. Int J Inj Contr Saf Promot 2006;13:187-9.

10. Na L, Gonghuan $Y$, Jiemin $M$, et al. Injury associated health risk factors in Chinese people in 2002. Chin J Epidemiol 2005;26:746-50.

11. Ministry of Public Security, Peoples' Republic of People's Republic of China. Statistical yearbook of the Bureau of Traffic Management. Beijing: Ministry of Public Security, Peoples' Republic of People's Republic of China, 2005. 
12. National Bureau of Statistics. People's Republic of China statistical yearbook, 2006. Beijing: People's Republic of China Statistics Press.

13. Guangzhou Health Bureau. Guangzhou health statistics annual 2003. Guangzhou: Guangdong Science and Technology Press, 2004.

14. Ruth AS, James LN, Tho BD-Z, et al. Effectiveness of primary

enforcement of safety belt laws and enhanced enforcement of safety belt laws: a summary of the guide to community preventive services systematic reviews. J Safety Res 2004;35:189-96.

15. Laxminarayan R, Chow J, Shahid-Salles S. Intervention cost-effectiveness: overview of main messages In: Jamison D, Breman J, Measham A, et al, eds. Disease control priorities in developing countries. 2nd edn. Oxford: Oxford Medical Publications, 1993:35-70.
16. World Health Organization. Macroeconomics and health: investing in health for economic development: report of the Commission on Macroeconomics and Health. Geneva: World Health Organization, 2001.

17. Australian Department of Foreign Affairs \& Trade. People's Republic of China Country Brief, August 2006. http://www.dfat.gov.au/geo/china/cb_index. html.pdf.

18. Glassbrenner D. Safety belt use in 2005: use rates in the States and Territories. Washington DC: NHTSA's National Center for Statistics and Analysis, 2005.

19. ARUP Transportation Planning. The 1994 Exposure Survey. Final Report. Prepared for VicRoads by ARUP Transportation Planning, 1995.

20. Houston DJ, Richardson LE. Getting Americans to buckle up: the efficacy of state seat belt laws. Accid Anal Prev 2005;37:1114-20. 